\title{
Shear Strength in Solder Bump Joints for High Reliability Photodiode Packages
}

\author{
Chong-Hee $\mathrm{Yu}^{1}$, Kyung-Seob $\mathrm{Kim}^{2}$ and Jun-Mo Yang ${ }^{3}$ \\ ${ }^{1}$ Electronics and Telecommunications Research Institute and Daejeon 305-350, Korea \\ ${ }^{2}$ Department of Electronic Engineering, Yeojoo Institute of Technology, Yeojoo 469-705, Korea \\ ${ }^{3}$ Memory R\&D Division, Hynix Semiconductor Inc., Icheon 467-701, Korea
}

\begin{abstract}
The shear strength and fracture surfaces of $\mathrm{Sn}-\mathrm{Pb}$ bump and $\mathrm{Au}$ stud bump for photodiode packages after isothermal aging testing were studied experimentally. $\mathrm{Al} / \mathrm{Au}$ stud bumps and $\mathrm{Cu} / \mathrm{Sn}-37$ mass $\% \mathrm{~Pb}$ solders were adopted, and aged at $373 \mathrm{~K}$ and $423 \mathrm{~K}$ for up to $900 \mathrm{hours}$ to analyze the effect of intermetallic compound (IMC). The shear strength decreased with aging time. The diffraction patterns of $\mathrm{Cu}_{6} \mathrm{Sn}_{5}$, scallopshaped IMCs, and planar-shape $\mathrm{Cu}_{3} \mathrm{Sn}$ were observed by transmission electron microscopy (TEM). The formation of Kirkendall voids with the growth of IMCs at the solder was found to be a possible mechanism for shear strength reduction. IMCs between Au stud bumps and Al pads were identified as $\mathrm{AlAu}_{2}$.
\end{abstract}

(Received June 2, 2003; Accepted August 22, 2003)

Keywords: solder bump, stud bump, shear strength, thermal aging, intermetallic compound, Kirkendall void

\section{Introduction}

Packaging technology is developing quickly to meet the requirements induced by the development of microelectronics industry. As the trend toward higher $\mathrm{I} / \mathrm{O}$, higher performance, and higher printed circuit board (PCB) manufacturing yield continues, ball grid array (BGA), chip scale package (CSP) and flip chip become choice for packaging, and there is no doubt that such kinds of packaging structures should be high density and fine pitch available. The flip-chip technologies include several mounting methods currently in use such as anisotropic conductive film/paste (ACF/ACP), controlled collapse chip connection (C4), stud bump bonding (SBB). ${ }^{1,2)}$ Among these flip-chip technologies, SBB is frequently used in a prototype development because of low cost and easy application without under bump metallurgy (UBM). In particular, the flip chip technology used for Au-Sn that includes the thermo-compression bonding process is actively studied because of high frequency characteristic of Au-Sn solder, ${ }^{3)}$ but considered the efficient transmission of optical signal, flip-chip using thermo-compression bonding process is limited because of the alignment of optical signal. Therefore, the study of flip-chip technology with the solder reflow process that has self-alignment characteristics is needed. To guarantee long-term reliability of flip-chip bonding technology, the reliability of the fine joint area must be investigated. Intermetallic compound (IMC), form during the reflow process for the formation of solder bump and practical operating temperature, is grown at the interface between solder and the UBM. The IMCs at the interface of the solder and the UBM cause cracks at the solder joint area owing to the brittleness, and weakens the overall shear strength. ${ }^{40)}$ Detailed knowledge of solder joints in photodiode packaging under thermal aging tests is important for the practical design and fabrication of reliable optoelectronic packaging. At present, the electronic packaging industry is actively searching for $\mathrm{Pb}$-free solders due to environmental concern of $\mathrm{Pb}$-based solders. The results of this work may lead to the fabrication of reliable $\mathrm{Pb}$-free photodiode packages for use in lightwave communication-system applications.

In this paper, the shear strength and fracture surface of Sn$\mathrm{Pb}$ and $\mathrm{Au}$ stud bumps were studied under various isothermal aging at $373 \mathrm{~K}$ and $423 \mathrm{~K}$. The effect of isothermal aging duration on the bump joint strength was studied by characterizing the microstructure and fracture surface of bump joints. There is a correlation between the IMC growth, fracturesurface morphology, and shear strength of $\mathrm{Sn}-\mathrm{Pb}$ and $\mathrm{Au}$ stud bumps under isothermal tests.

\section{Experimental Details}

The high-speed photodiode were used in this experiment, and the bump structure consisted of an anode, cathode, and a dummy bumps. Dummy bump was formed for a balance chip. The chip dimensions were $460 \mu \mathrm{m} \times 250 \mu \mathrm{m} \times 100 \mu \mathrm{m}$. Bonding pad sizes were $80 \mu \mathrm{m}$ and $100 \mu \mathrm{m}$ in diameter. Au stud bumps were formed directly on the $2.0 \mu \mathrm{m}$ thickness $\mathrm{Al}$ pad by using wire ball bonding technique. A coining process was applied to make the height of the bump uniform. For solder bumps, Al-1\%Si/TiW/Cu layers were sputter deposited on the $0.2 \mu \mathrm{m}$ thick dry-oxide layer at thickness ratio of $1.0 \mu \mathrm{m} / 2.0 \mu \mathrm{m} / 0.4 \mu \mathrm{m}$. A $10 \mu \mathrm{m}$-thick electroplating $\mathrm{Cu}$ layer was formed to ensure good wetting with the solder and to prevent the substrate metal from being consumed due to the melting or growth of the IMC. A 30 to $50 \mu \mathrm{m}$ thick photoresist (PR) was hard baked to define the solder bump by electroplating. These processes were followed by PR stripping, UBM etching, and reflow process. After the flux was applied, reflow process was carried out by using a reflow equipment that had infrared and hot air convection heating system. The overall reflow time was 5 minutes, and the velocity of the conveyer was $0.55 \mathrm{~m} / \mathrm{min}$. The peak reflow temperature was $483 \pm 278 \mathrm{~K}$ for 45 seconds. The time above liquidus state was 60 seconds. WS609 water-soluble flux was used to remove the oxides and to form a uniform bump. For $\operatorname{pad}(\mathrm{UBM})$ sizes of $80 \mu \mathrm{m}$ and $100 \mu \mathrm{m}$ in diameter, respectively, the diameters of the solder bumps ranged from $95 \mu \mathrm{m}$ to $99 \mu \mathrm{m}$ and from $120 \mu \mathrm{m}$ to $135 \mu \mathrm{m}$, respectively. The average heights of bumps were $83 \mu \mathrm{m}$ and $93 \mu \mathrm{m}$ with on 


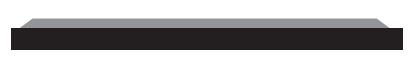

(a)

(b)

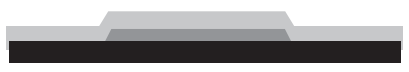

(c)

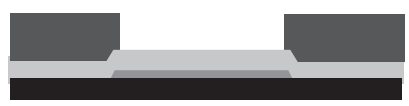

(d)

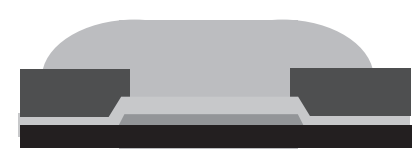

(e)

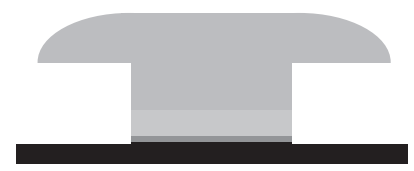

(f)

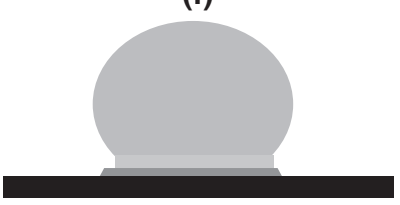

(g)
Fig. 1 Experimental procedure of the flip chip solder bumping on electroplating; (a) Al sputter deposition (b) Al patterning (c) UBM deposition (d) thick PR coating (e) solder electroplating (f) PR strip and UBM etching $(\mathrm{g})$ solder reflow.

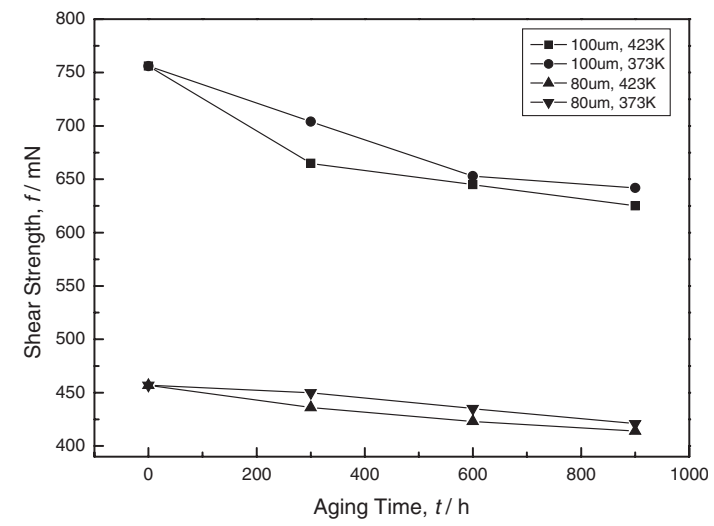

Fig. 3 Relation between aging time and shear strength with variable aging temperature and pad sizes of solder bump.
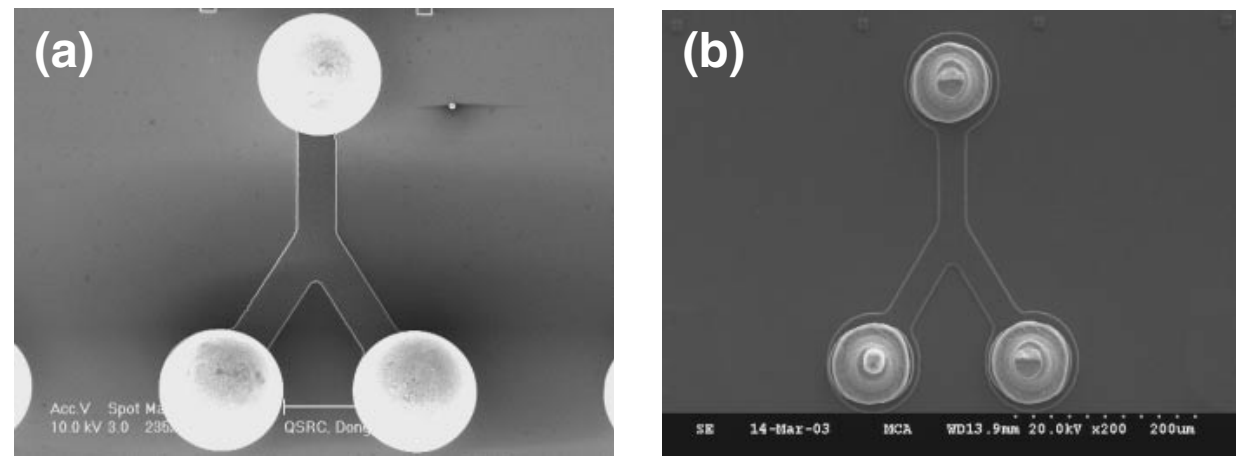

Fig. 2 Shape and size of photodiode; (a) solder bump (b) Au stud bump.

error of $1 \%$. Figure 1 shows a schematic diagram of solder bump formation, and Fig. 2 shows the shapes and sizes of the solder bump and Au stud bump.

To analyze the effect of aging time and temperature, the samples were aged at isothermal temperatures of $373 \mathrm{~K}$ and $423 \mathrm{~K}$ for 300,600 , and 900 hours. After samples were aged, the shear strength was measured by using system 552 (Royce). The tip of the machine moved at $0.3 \mathrm{~mm} / \mathrm{s}$. The distance between the UBM surface and the tip was $2.0 \mu \mathrm{m}$. The shear strengths of the samples at each condition were measured on 30 bumps from 10 samples. The average value of the strengths was calculated, discarding the maximum and minimum values. SEM was used to observe the fractured surface of sheared solder bumps and Au stud bumps. Using TEM and TEM diffraction pattern, the IMC layers and the microscopic structure of the interface between the bump and the UBM were analyzed. TEM samples were prepared with a focused ion beam (FIB) that has $\mathrm{Ga}^{+}$ion source at an acceleration voltage of $30 \mathrm{keV}$. FIB samples were made by Micrion 2100. Finally, electro-transparent samples were made by micro milling with a $100 \mathrm{pA}$ ion beam. The TEM sample was observed with JEM-2010UHR (JEOL) and HD2000 (Hitachi) at on acceleration voltage of $200 \mathrm{keV}$.

\section{Results and Discussion}

Pad sizes of $80 \mu \mathrm{m}$ and $100 \mu \mathrm{m}$ in diameter were sheared to analyze the relation between the shear strength and dimensions of a solder bump. The effect of aging temperature and aging time on the shear strength was investigated by shear test after thermal aging. Figure 3 shows the shear strength variation of $\mathrm{Sn}-37$ mass $\% \mathrm{~Pb}$ solders as a function of aging temperatures and times. Shear strengths of two different pad size samples were varied with aging temperatures and times. The average initial shear strengths of $100 \mu \mathrm{m}$ and $80 \mu \mathrm{m}$ pad size samples were $756 \mathrm{mN}$ and $457 \mathrm{mN}$, respectively. After 900 hours of aging at $423 \mathrm{~K}$, the average shear strength of $100 \mu \mathrm{m}$ pad size samples was $625 \mathrm{mN}$, a decrease of about $21 \%$ from the initial value, and the average shear strength of $80 \mu \mathrm{m}$ pad size samples was $414 \mathrm{mN}$, a decrease of $10 \%$ from the initial shear strength. After 900 hours of aging at the $373 \mathrm{~K}$, the average shear strengths of $100 \mu \mathrm{m}$ and $80 \mu \mathrm{m}$ pad size samples decreased of about $18 \%$ and $8 \%$ from corresponding initial values, respectively. As the result of thermal aging, the shear strength tended to decrease with aging time and temperature, and these decreases were due to 


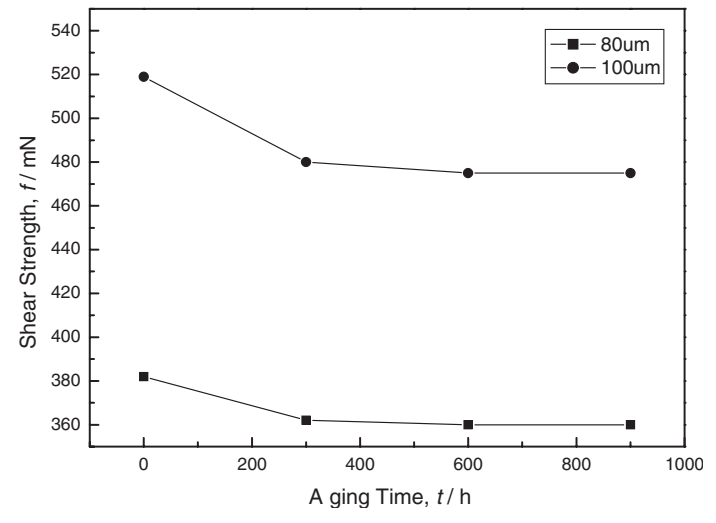

Fig. 4 Relation between aging time and shear strength of Au stud bump.

the growth of $\mathrm{Pb}$-rich from the reaction of $\mathrm{Cu}$ and $\mathrm{Sn}$.

Figure 4 shows the shear strength of Au stud bumps at various aging times at $423 \mathrm{~K}$. After 300 hours of aging, the average shear strength of stud bump with the pad size of $80 \mu \mathrm{m}$ in diameter was $362 \mathrm{mN}$, a decrease of $5 \%$ from the initial strength. As shown in Fig. 4, there were no differences in shear strength after more than 300 hours of aging. For Au stud bumps, the average initial strength of $80 \mu \mathrm{m}$ pad size samples was $382 \mathrm{mN}$. These values were a decrease of $18 \%$ from the initial shear strength of solder bumps with same pad size.

Figure 5 shows the fractured surface of solder before aging. As shown in Fig. 5, the fractured surface remained circular corresponding to the contact forms of the UBM and the solder before aging. And as shown on the right side in the enlarged figure, the fracture mode was considered as the partial ductile fracture mode associated with solder elements, $\mathrm{Sn}$ and Pb. The white arrows in Fig. 5 to Fig. 6 and Fig. 8 to Fig. 9 represent the direction of the tester tip in the shear test. Figure 6 shows the fracture surface after aging for 900 hours at $423 \mathrm{~K}$. This surface also indicates ductile fracture, the principal fracture mode on $\mathrm{Cu}$. But partial brittle fracture was observed as well as ductile fracture with aging time. Generally, $\mathrm{Cu}-\mathrm{Sn}\left(\mathrm{Cu}_{6} \mathrm{Sn}_{5}+\mathrm{Cu}_{3} \mathrm{Sn}\right)$ IMC grew in the shape of straight line until the aging below 900 hours. However, the thickness growth of the sample that had been aged for over 1500 hours was parabolic. Yu et al. reported that the growth of IMC layer is controlled by the diffusion. ${ }^{8)}$

Figure 7 shows the different microstructures of IMC morphologies according to the aging time. As shown in Fig. 7 , while the aging time increases, the IMC grains get coarsen. Consequently, the IMC growth and grain coarsening decrease the shear strength. Figures 8 and 9 show the fracture surface of Au stud bumps before aging and after 300 hours of aging, respectively. A wire ball bonding trace was observed on every fracture surface. The $\mathrm{Al}$ elements detected at the fractured surface of the sample after aging indicated the exposure of IMC formed between $\mathrm{Al}$ and Au. The path of fracture gradually moved from inside of the solder to the interface of the IMC layer. A stable $2.3 \mu \mathrm{m}$ to $3.0 \mu \mathrm{m} \mathrm{Al}-\mathrm{Au}$ $\mathrm{IMC}$, was formed at the joint interface between $\mathrm{Al}$ pad and Au stud bump, and large amounts of $\mathrm{Al}$ pad were consumed
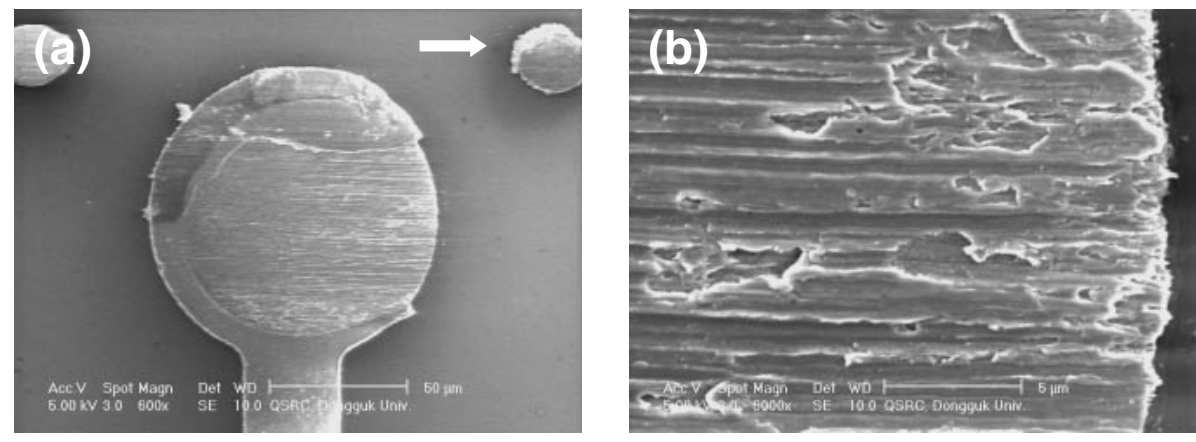

Fig. 5 Fractured surface of a sheared solder bump before aging; (a) whole image (b) higher magnification.
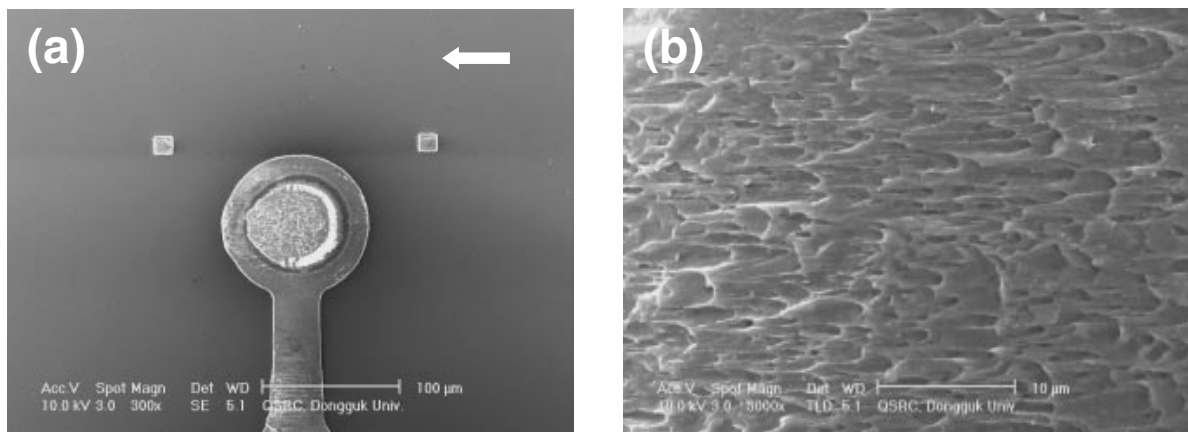

Fig. 6 Fractured surface of a sheared solder bump after aging at $423 \mathrm{~K}$ for 900 hours; (a) whole image (b) higher magnification. 

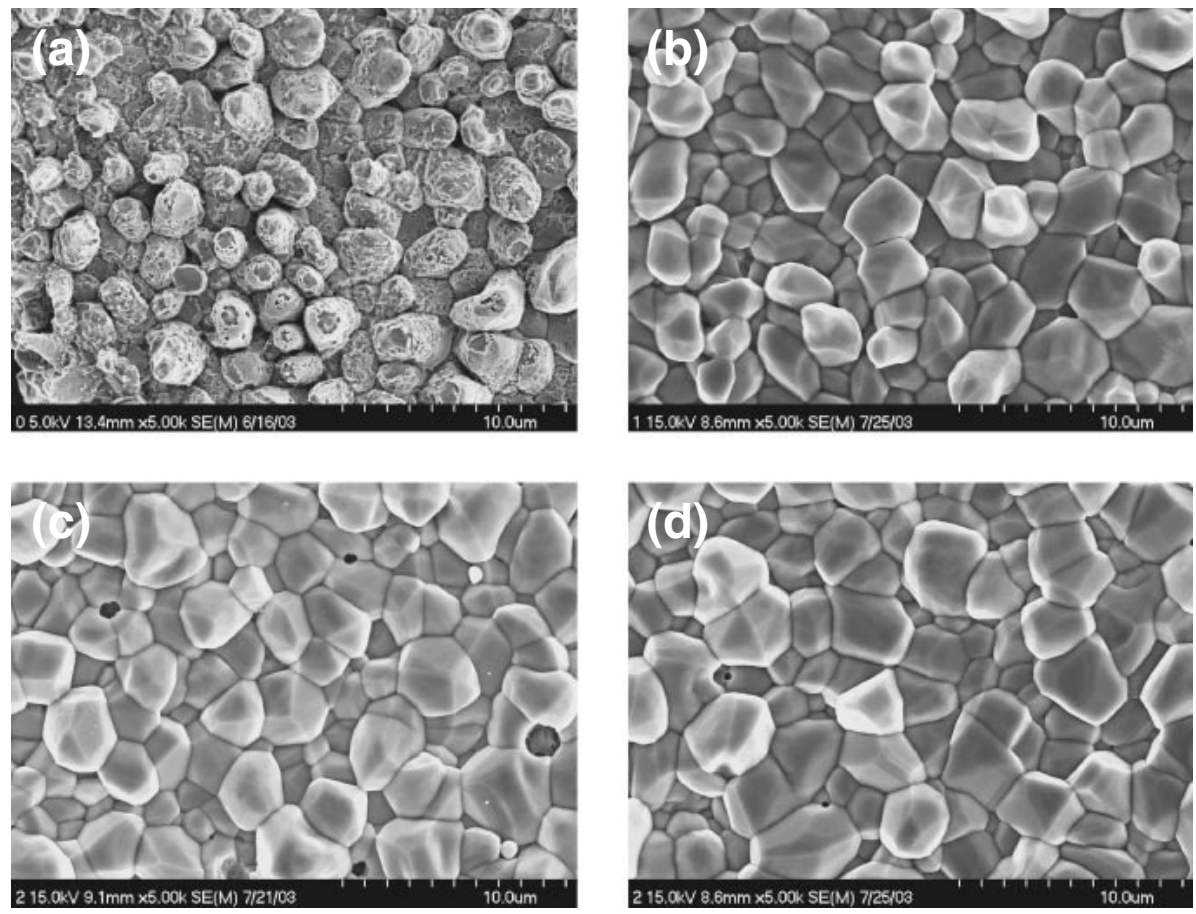

Fig. 7 Microstructures of different morphologies of IMC in plan views; (a) before aging (b) 300 hours (c) 600 hours (d) 900 hours. Solder was etched away to reveal the $\mathrm{Cu}_{6} \mathrm{Sn}_{5}$ grains.
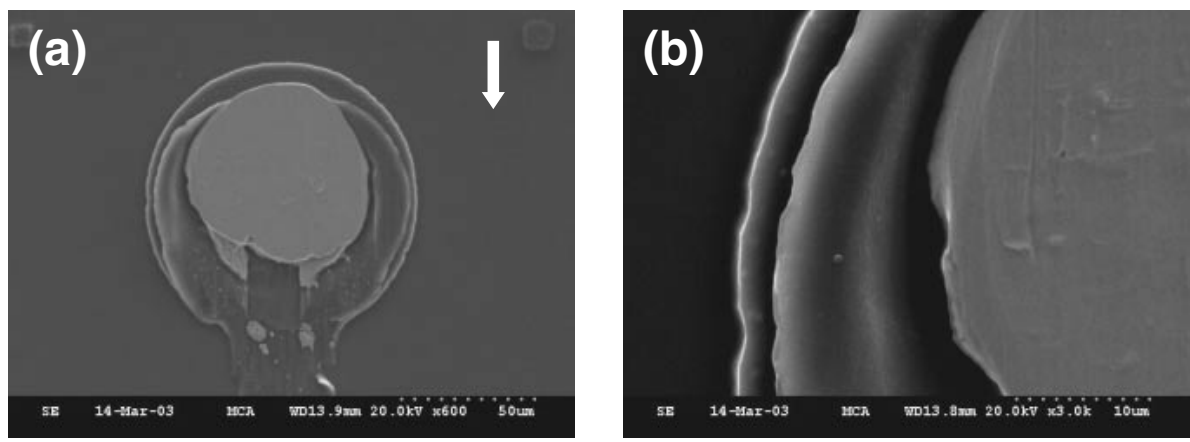

Fig. 8 Fractured surface of a sheared Au stud bump before aging; (a) whole image (b) higher magnification.
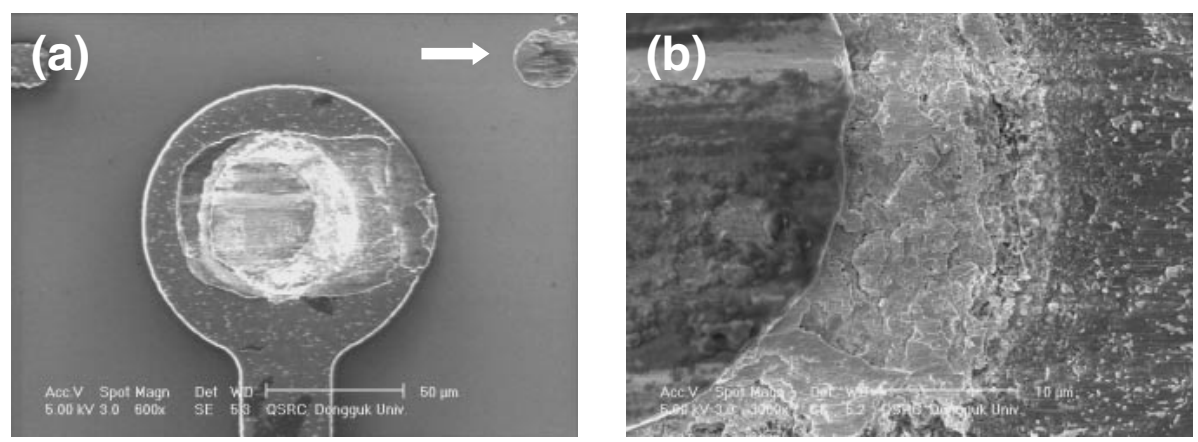

Fig. 9 Fractured surface of a sheared Au stud bump after aging at $423 \mathrm{~K}$ for 300 hours; (a) whole image (b) higher magnification. 

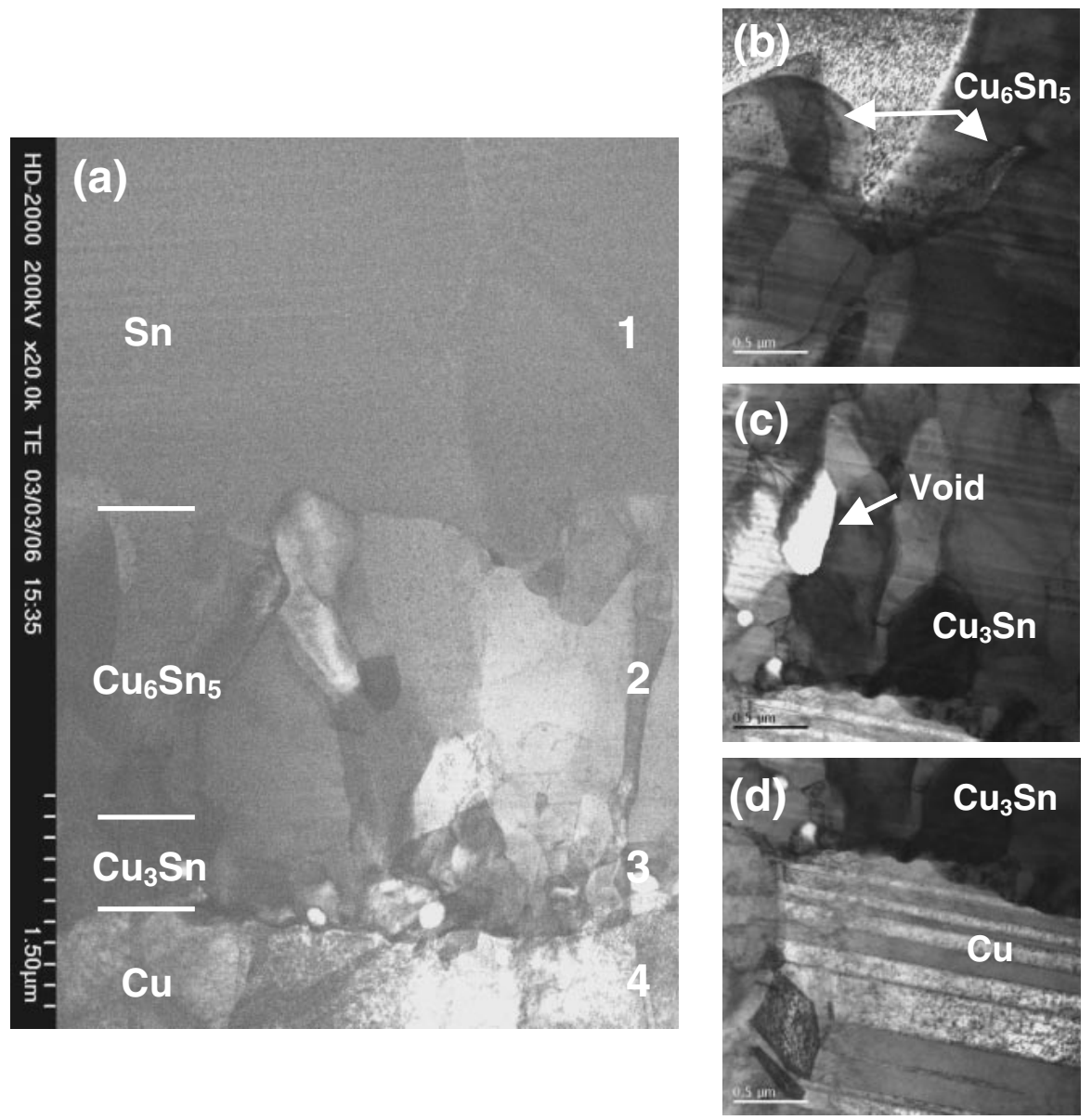

Fig. 10 (a) TEM image and electron diffraction patterns showing interfacial reaction of solder and UBM (b) higher magnification TEM image of $\mathrm{Cu}_{6} \mathrm{Sn}_{5}$ grain (c) $\mathrm{Cu}_{3} \mathrm{Sn}$ grain and the Kirkendall voids (b) $\mathrm{Cu}$.

during the reflow soldering. The composition was 4 mass $\%$ $\mathrm{Al}$ and 96 mass\% Au as obtained by energy dispersive X-ray (EDX). The Au mass\% of remains was a little higher than that of $\mathrm{AlAu}_{2}$. ${ }^{9}$

Figure 10 shows bright-field cross-section TEM images of the interface between the solder and UBM after 300 hours of aging at $423 \mathrm{~K}$. Microstructures of the solder and the IMCs layer were clearly observed. The specimens aged for 300 hours displayed two distinct intermetallic layers of $\mathrm{Cu}_{3} \mathrm{Sn}$ and $\mathrm{Cu}_{6} \mathrm{Sn}_{5}$. The thickness of the layers of these intermetallic compounds varied with the solder system. As the aging time increased, the IMCs layer grew, but slower. The dark area, region 1 in Fig. 10(a), is the Sn-rich phase. The microstructures, $\mathrm{Sn}$-rich and $\mathrm{Pb}$-rich, gradually grew as aging time increased. Region 2 is $\mathrm{Cu}_{6} \mathrm{Sn}_{5}$, and its thickness ranged from 1.5 to $2.8 \mu \mathrm{m}$. $\mathrm{Cu}_{3} \mathrm{Sn}$ grew to a thickness of 0.7 to $0.8 \mu \mathrm{m}$, and was located in region 3. Region 4, the bright area, is $\mathrm{Cu}$. As shown in Fig. 10, $\mathrm{Cu}_{6} \mathrm{Sn}_{5}$ grew to the shape of a scallop, and its grain was larger than the grain of the relatively planarshaped $\mathrm{Cu}_{3} \mathrm{Sn}$. $\mathrm{Cu}_{6} \mathrm{Sn}_{5}$ grew into scallop shape because of the irregular growth from the fast rate of interstitial diffusion. This small columnar holes along the interface between $\mathrm{Cu}$ and $\mathrm{Cu}_{3} \mathrm{Sn}$ are Kirkendall voids. The $\mathrm{Cu}_{3} \mathrm{Sn}$ grains are grouped into clusters and there are Kirkendall voids in the center of each cluster. These voids had diameters in the range of 100 to $250 \mathrm{~nm}$. The appearance of voids in Fig. 10 is due to the diffusion of $\mathrm{Cu}$ atoms during the growth of $\mathrm{Cu}_{3} \mathrm{Sn}$. The brittle characteristics of the $\mathrm{Cu}-\mathrm{Sn}$ IMC and the Kirkendall voids at the electroplated $\mathrm{Cu}$ UBM-Sn containing solder system can cause brittle bump failure, with a decreased bump shear strength. Figures 10(b), (c) and (d) are the enlarged photographs of each IMC. Figure 11 shows the diffraction patterns of each region in Fig. 10(a). From the results of Figs. 10 and 11, it was confirmed that two reaction layers between $\mathrm{Cu}$ and $\mathrm{Sn}$ were formed, and their structure evaluated to be $\mathrm{Cu}_{6} \mathrm{Sn}_{5}$ (hexagonal phase, JCPDS 02-0713) of the upper layer with a large grain size and $\mathrm{Cu}_{3} \mathrm{Sn}$ (hexagonal phase, JCPDS 03-1010) of the bottom layer with a small grain size. $\mathrm{Cu}$ and $\mathrm{Sn}$ were formed with cubic phase, respectively.

\section{Conclusion}

Au stud bumps and eutectic solder bumps were formed on the surface of circular pad of a photodiode, which is used in high-speed optical telecommunication modules. The shear strength between the bump and the UBM and the variation of the strength according to thermal aging were measured by shear test. IMC growth, fracture surface morphology was also observed. 

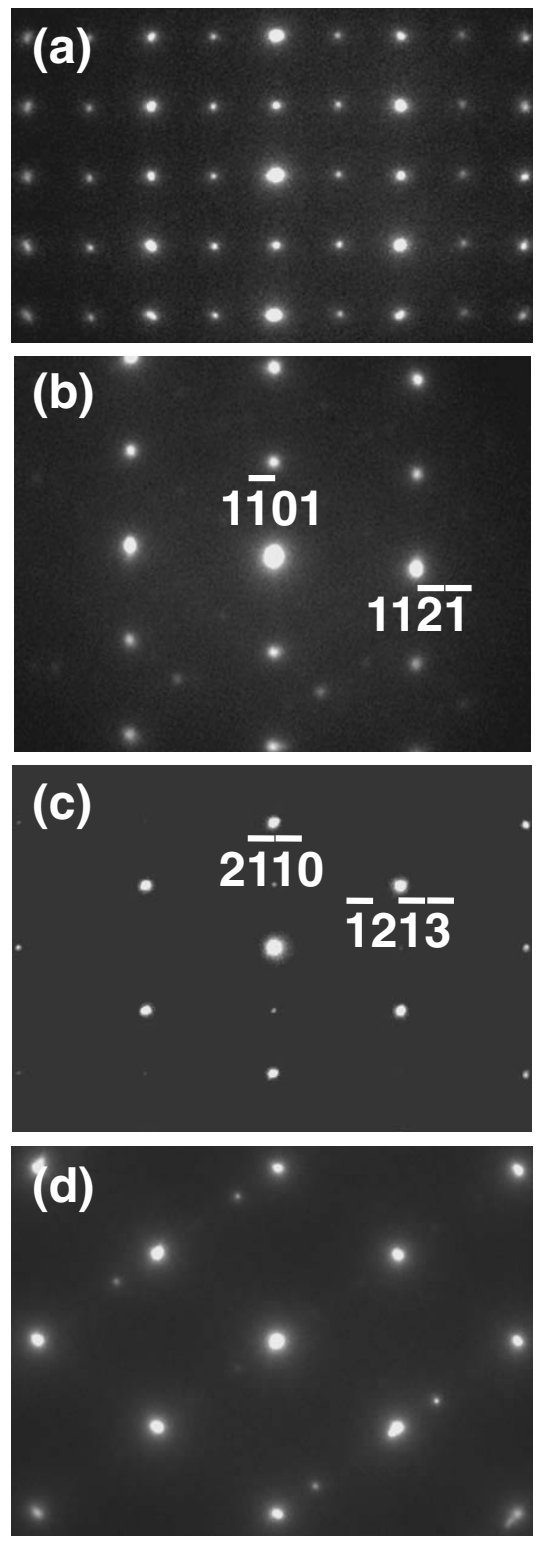

Fig. 11 Diffraction patterns taken from layers 1; (a), 2 (b), 3 (c) and 4 (d) The diffraction patterns of $\mathrm{Cu}_{6} \mathrm{Sn}_{5}$ and $\mathrm{Cu}_{3} \mathrm{Sn}$ correspond to the [121 $\left.1 \overline{3}\right]$ and $[0 \overline{1} 11]$ zone axes, respectively.
(1) As the aging time increased, the shear strength of the two kinds of the solders decreased. The joint strengths more at relatively higher aging temperatures and with larger pad size. In the case of stud bumps, the joint strength did not change after more than 300 hours of aging.

(2) Scallop-shaped $\mathrm{Cu}_{6} \mathrm{Sn}_{5}$ of 1.5 to $2.8 \mu \mathrm{m}$ thickness and $0.7 \mu \mathrm{m}$ to $0.8 \mu \mathrm{m}$ thick planar $\mathrm{Cu}_{3} \mathrm{Sn}$ grew throughout the 300 hours of aging at $423 \mathrm{k}$. In the case of $\mathrm{Au}$ stud bumps, the $2.3 \mu \mathrm{m}$ thick Al-Au IMC, grew throughout the 300 hours of aging at $423 \mathrm{~K}$.

(3) After 300 hours of aging, the average shear strength of stud bump samples was $362 \mathrm{mN}$, a decrease of $5 \%$ from the initial value, and the shear strength did not change after more than 300 hours of aging.

(4) The Kirkendall voids, which formed with the growth of the IMC of the Sn-37 mass\% Pb solder with aging time was also a possible mechanism for the shear strength reduction.

\section{REFERENCES}

1) R. Tummala: Fundamentals of Microsystems Packaging, (McGrawHill, New York, 2001) pp. 368-370.

2) E. K. Young and I. Turlink: IEEE Trans. Comp. Hybrids, Manufact. Technol. 14 (1991) 549-559.

3) S. Zama, D. F. Baldwin and T. Hikami: Elec. Comp. \& Tech. Conf. 50 (2000) 1111-1117.

4) R. F. Pinizzotto and E. G. Jacobs: IEEE/IRPS (1993) 209-213.

5) D. R. Frear: The Mechanics of Solder Alloy Interconnects, (Van Nostrand Reinhold Wiley, New York, 1994) ch. 3.

6) C. Chun: IEEE Trans. Microwave Theory Tech. 45 (1997). 1948-1954.

7) X. Huang and S. W. Rickly Lee: Elec. Comp. \& Tech. Conf. 52 (2002) 968-973.

8) C. H. Yu, K. S. Kim, and N. K. Kim: Mater. Trans. 43 (2002) 32343238.

9) A. Lida and S. Nakamura: Jpn. J. Appl. Phys. 36 (1997) 3655-3661.

10) M. T. Sheena, C. M. Changa: J. Electron. Mater. 31 (2002) 895-902. 